\title{
Failure to perceive increased risk of fracture in women 55 years and older: the Global Longitudinal Study of Osteoporosis in Women (GLOW)
}

\author{
E. S. Siris • S. Gehlbach • J. D. Adachi • S. Boonen • R. D. Chapurlat • \\ J. E. Compston • C. Cooper • P. Delmas • A. Díez-Pérez • F. H. Hooven • \\ A. Z. LaCroix • J. C. Netelenbos • J. Pfeilschifter • M. Rossini • C. Roux • K. G. Saag • \\ P. Sambrook • S. Silverman • N. B. Watts • A. Wyman • S. L. Greenspan
}

Received: 10 December 2009/Accepted: 2 February 2010/Published online: 1 April 2010

(C) The Author(s) 2010. This article is published with open access at Springerlink.com

\begin{abstract}
Summary We compared self-perception of fracture risk with actual risk among 60,393 postmenopausal women aged $\geq 55$ years, using data from the Global Longitudinal Study of Osteoporosis in Women (GLOW). Most postmenopausal women with risk factors failed to appreciate their actual risk for fracture. Improved education about osteoporosis risk factors is needed.
\end{abstract}

Pierre Delmas is deceased.

\section{E. S. Siris $(\bowtie)$}

Department of Medicine, Columbia University Medical Center, 180 Fort Washington Avenue, Harkness Pavilion 9-964,

New York, NY 10032, USA

e-mail: es27@columbia.edu

J. D. Adachi

St. Joseph's Hospital, McMaster University,

Hamilton, ON, Canada

S. Boonen

Leuven University Center for Metabolic Bone Diseases,

Division of Geriatric Medicine, Katholieke Universiteit Leuven,

Leuven, Belgium

R. D. Chapurlat $\cdot$ P. Delmas

Division of Rheumatology, Hôpital E. Herriot, INSERM U831, Université de Lyon,

Lyon, France

J. E. Compston

School of Clinical Medicine, Addenbrooke's Hospital,

University of Cambridge,

Cambridge, UK

C. Cooper

MRC Epidemiology Resource Centre,

University of Southampton, Southampton General Hospital,

Southampton, UK
Introduction This study seeks to compare self-perception of fracture risk with actual risk among postmenopausal women using data from GLOW.

Methods GLOW is an international, observational, cohort study involving 723 physician practices in 17 sites in ten countries in Europe, North America, and Australia. Participants included 60,393 women $\geq 55$ years attended by their

C. Cooper

Institute of Musculoskeletal Sciences, University of Oxford,

Oxford, UK

\section{A. Díez-Pérez}

Department of Medicine, Hospital del Mar-IMIM-Autonomous,

University of Barcelona,

Barcelona, Spain

S. Gehlbach • F. H. Hooven • A. Wyman

Center for Outcomes Research, UMASS Medical School,

Worcester, MA, USA

\section{S. L. Greenspan}

University of Pittsburgh, Pittsburgh, PA, USA

\section{A. Z. LaCroix}

Fred Hutchinson Cancer Research Center,

Seattle, WA, USA

J. C. Netelenbos

Department of Endocrinology, VU University Medical Center, Amsterdam, The Netherlands

\section{J. Pfeilschifter}

Department of Internal Medicine III, Alfried Krupp Krankenhaus, Essen, Germany 
physician during the previous 24 months. The sample was enriched so that two thirds were $\geq 65$ years. Baseline surveys were mailed October 2006 to February 2008. Main outcome measures were self-perception of fracture risk in women with elevated risk vs women of the same age and frequency of risk factors for fragility fracture.

Results In the overall study population, $19 \%(10,951 / 58,434)$ of women rated their risk of fracture as a little/much higher than that of women of the same age; $46 \%(27,138 / 58,434)$ said it was similar; $35 \%(20,345 / 58,434)$ believed it to be a little/much lower. Among women whose actual risk was increased based on the presence of any one of seven risk factors for fracture, the proportion who recognized their increased risk ranged from $19 \%$ for smokers to $39 \%$ for current users of glucocorticoid medication. Only 33\% (4,185/ 12,612 ) of those with $\geq 2$ risk factors perceived themselves as being at higher risk. Among women reporting a diagnosis of osteopenia or osteoporosis, only $25 \%$ and $43 \%$, respectively, thought their risk was increased.

Conclusion In this international, observational study, most postmenopausal women with risk factors failed to appreciate their actual risk for fracture.

Keywords Osteoporosis · Postmenopausal $\cdot$ Risk factor . Women

\section{Introduction}

Clinical risk factors associated with an increased probability of osteoporosis-associated fractures in postmenopausal women are well documented, and several interventions have been shown to lower fracture risk [1-3]. However,

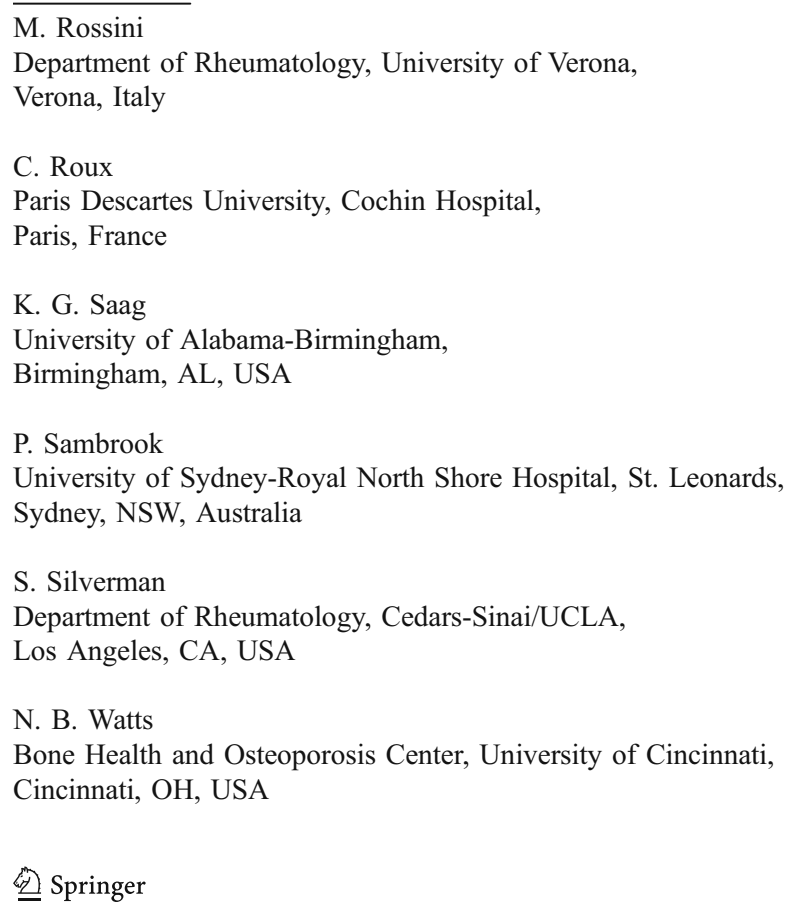

there is evidence that many individuals who have these risk factors and are candidates for preventive care to reduce the likelihood of future fractures go unrecognized and untreated $[4,5]$. While responsibility for this gap is assumed to lie largely within the healthcare system, individuals also need to recognize and understand the risks that predispose them to fracture in order to be motivated to both seek medical care and adhere to recommendations made if effective prevention strategies are to be successful. Several studies suggest that under-appreciation of osteoporosis-related fracture risk may play a role in explaining the evaluation and treatment gap. In community samples of women from South Australia, there was a lack of knowledge of osteoporosis risk factors overall; risk was wrongly selfperceived to be higher among younger (age 45 to 54 years) than older ( $>55)$ women [6]. In a community-based study of women with an average age of 60 (85\% greater than age 50) from the Southwestern United States, only $16 \%$ perceived themselves to be at higher risk of osteoporosis compared with $63 \%$ who thought their risk was low [7]. Among a group of Canadian patients with recent fragility fractures, fewer than $50 \%$ believed they were at increased risk of future fractures [8].

To explore the role that patient perceptions might play in the current setting of both under-diagnosis and under-treatment of those at increased risk of fracture, we assessed self-perceived risk of fracture among women 55 years of age and older. We compared perceived risk with self-reported characteristics known to increase fracture risk, including risk factors utilized by the FRAX ${ }^{\circledR}$ algorithm (the recently released World Health Organization 10-year absolute fracture risk assessment tool [9]), using data from the Global Longitudinal Study of Osteoporosis in Women (GLOW). Our goals were to gauge the degree of concordance between perceived and actual risk and to identify the factors that women most recognized as placing them at increased fracture risk.

\section{Methods}

Setting

GLOW is an observational cohort study that is being conducted in physician practices in 17 sites in ten countries (Australia, Belgium, Canada, France, Germany, Italy, Netherlands, Spain, UK, and USA) in Australia, Europe, and North America. These sites are located in major population centers. Clinical investigators at each of the 17 sites constitute the GLOW Scientific Advisory Board and are responsible for the management of the study. Details of the study design and methods have been previously described [10]. In brief, practices typical of each region were recruited through primary care networks organized for 
administrative, research, or educational purposes or by identifying all physicians in a geographic area. Physician networks included regional health system-owned or managed practices, health maintenance organizations, independent practice associations, and other primary care practice networks. Networks established for the purpose of general medical research were used only if they were not established exclusively for osteoporosis research and did not consist primarily of physicians whose primary focus was academic. Each study site obtained ethics committee approval to conduct the study in the specific location.

\section{Definitions}

Primary care physicians were defined as those who spent most of their time providing primary healthcare to patients and included internists, family practitioners, and general practitioners. If the physician network or study area included more eligible physicians than were required to recruit a sufficient number of patients, a random sample of those physicians within the network or study was invited.

Each practice provided a list of the names and addresses of women aged 55 years and older who had been attended by their physician in the past 24 months. Sampling was stratified by age to ensure that two thirds consisted of women 65 years of age and older. In each practice, we recruited from all eligible women 65 and over and from a random sample of half that number less than 65 years. Patients were excluded if they were unable to complete the study survey due to cognitive impairment, language barriers, institutionalization, or were too ill.

\section{Questionnaire design}

Questionnaires were designed to be self-administered and covered domains that included: patient characteristics and risk factors, perception about fracture risk and osteoporosis, medication use (currently taking or ever taken), medical diagnoses, healthcare use and access, physical activity, and physical and emotional health status. Where possible, items from published validated instruments were used, including the National Health and Nutrition Examination Survey [11], EuroQol EQ-5D [12], and SF-36 [13] (physical function component).

Self-reports of personal risk factors included: current weight and height, parental hip fracture, two or more falls in the past 12 months, current use of cortisone or prednisone, diagnosis of rheumatoid arthritis, personal history of fracture (clavicle, arm, wrist, spine, rib, hip, pelvis, upper leg, lower leg, and ankle) since age 45, current cigarette smoking, and consumption of three or more units of alcohol daily. With the exception of falls, these risk factors are all included in the FRAX tool [9].
Subjects were considered to be taking antiosteoporosis medications if they reported current use of alendronate, calcitonin, estrogen, etidronate, ibandronate, pamidronate, PTH [1-84], raloxifene, risedronate, strontium ranelate, teriparatide, tibolone, or zoledronate. Respondents rated their perceived risk of fracture compared with women of the same age using a five-point scale that ranged from "much lower" to "much higher."

Baseline questionnaires along with invitations to participate in the study signed by the local principal investigator were mailed to all potential subjects. Non-respondents were followed up with sequential postcard reminders, second questionnaires, and telephone interviews.

The FRAX tool [9] is a risk assessment survey that calculates the 10-year probability of hip fracture and the 10year probability of major osteoporosis-related fracture (clinical spine, forearm, hip, or proximal humerus fracture). It is composed of 11 variables: age, sex, weight, height, previous fracture as an adult, parental hip fracture, current cigarette smoking, current (or 3 months of past) use of glucocorticoids, diagnosis of rheumatoid arthritis, consumption of three or more units of alcohol daily, and secondary osteoporosis. It can be used with or without the addition of the bone mineral density derived T-score at the femoral neck. For this analysis we defined the FRAX risk factors as follows: previous adult fracture included any fracture occurring after age 45; glucocorticoid use was limited to current use only; and rheumatoid arthritis was not included as a variable because of lack of physician verification. "Secondary osteoporosis" was defined as reported type 1 diabetes, menopause before the age of 45 years, ulcerative colitis, celiac disease, and use of hypogonadism-inducing aromatase inhibitor medications (anastrozole, letrozole, or exemestane). Bone density testing may have been obtained in some subjects by their primary physicians as part of routine care, but since it was not performed as a component of the GLOW protocol, bone density was not included in this analysis. For the calculation of cumulative risk factors, weight less than $125 \mathrm{lb}(57 \mathrm{~kg})$ was used as the low weight variable.

\section{Statistical analysis}

Patients' perceived risk of fracture was compared with the presence of individual and combined numbers of risk factors. To help ensure regional results were not influenced by regional differences in age, regional proportions were age standardized to reflect the age distribution of the entire GLOW population, using four age groups: 55-64, 65-74, $75-84$, and $\geq 85$ years. For all other analyses three age groups were used: $55-64,65-74$, and $\geq 75$ years. All other categorical variables are reported as raw frequencies. A multiple logistic regression was used to estimate associa- 
tions between "much or a little higher" perception of fracture risk and the seven individual FRAX risk factors; estimates for number of FRAX factors and osteoporosis diagnosis are from separate logistic regressions models. We did not adjust for age, as the outcome is perceived risk compared to women of the same age.

\section{Results}

Patient characteristics

A total of 60,393 patients from practices of 723 physicians were enrolled in the study between October 2006 and February 2008. Approximately 25,000 women came from eight sites and 274 physician practices in Europe; 28,000 subjects were from 255 practices in the United States (US), and almost 7000 patients came from 86 practices in Canada and Australia. Among these women, 35\% (20,345/58,434) rated their risk of fracturing or breaking a bone to be "much lower" or "a little lower" than that of women of the same age, $46 \%(27,138 / 58,434)$ said their risk was "about the same," and 19\% $(10,951 / 58,434)$ rated their risk as "a little higher" or "much higher" than women of the same age (Table 1).
Subgroup analyses

When perceptions were viewed by age, the distributions were similar for the three age groups (Table 1), with a slightly greater proportion $(21 \%, 3,164 / 10,951)$ of women 75 years and older considering themselves to be at higher risk for fracture. Risk perception varied modestly by study region, ranging from $14 \%(1,893 / 13,334)$ of women from Northern Europe considering themselves to be at increased risk, to $20 \%(2,220 / 10,887 ; 5,627 / 27,466)$ of those from southern European and US sites.

Twenty-four percent $(14,183 / 58,935)$ of women reported having had a fracture since the age of $45,17 \%(9,189 / 53,663)$ reported a parental hip fracture, and $16 \%(9,436 / 57,900)$ had weight $<125 \mathrm{lb}$ (Table 2). Secondary osteoporosis was selfreported in $21 \%(12,403 / 57,974)$ of women, with menopause before the age of 45 years the most prevalent $(15 \%, 8,632$ / $59,399)$ of the four variables that comprised the diagnosis in this analysis. Only $9 \%(5,484 / 59,816)$ of the women were current cigarette smokers and fewer than 1\% (290/59,813) consumed more than 20 alcoholic drinks per week. When combinations of risk factors were evaluated, 39\% (23,772/ 60,392 ) of women said they had no risk factors, $39 \%$ $(23,622 / 60,392)$ had a single risk factor, and $22 \%(12,998 /$ $60,392)$ reported two or more risk factors.

Table 1 Perception of fracture risk compared with women of same age, by patient characteristic $(n=60,393)$

\begin{tabular}{|c|c|c|c|}
\hline \multirow[t]{2}{*}{ Group } & \multicolumn{3}{|c|}{ Perception of risk compared with women of same age (\%) } \\
\hline & Much or a little lower $(n=20,345)$ & About the same $(n=27,138)$ & Much or a little higher $(n=10,951)$ \\
\hline All women & $35(20,345 / 58,434)$ & $46(27,138 / 58,434)$ & $19(10,951 / 58,434)$ \\
\hline \multicolumn{4}{|l|}{ Age group (years) } \\
\hline 55 to 64 & $33(7,374 / 22,632)$ & $49(11,192 / 22,632)$ & $18(4,066 / 22,632)$ \\
\hline 65 to 74 & $37(7,574 / 20,672)$ & $45(9,377 / 20,672)$ & $18(3,721 / 20,672)$ \\
\hline$\geq 75$ & $36(5,397 / 15,130)$ & $43(6,569 / 15,130)$ & $21(3,164 / 15,130)$ \\
\hline \multicolumn{4}{|l|}{ Region $^{\mathrm{a}}$} \\
\hline Australia & $37(1,049 / 2,865)$ & $46(1,324 / 2,865)$ & $17(492 / 2,865)$ \\
\hline Canada & $33(1,286 / 3,882)$ & $48(1,877 / 3,882)$ & $19(719 / 3,882)$ \\
\hline \multirow[t]{3}{*}{ Northern Europe ${ }^{b}$} & $33(4,427 / 13,334)$ & $53(7,014 / 13,334)$ & $14(1,893 / 13,334)$ \\
\hline & $(26-47)$ & $(38-61)$ & $(13-15)$ \\
\hline & $(706 / 2,715-1,556 / 3,298)$ & $(1,244 / 3,298-1,678 / 2,715)$ & $(331 / 2,715-498 / 3,298)$ \\
\hline \multirow[t]{3}{*}{ Southern Europe ${ }^{c}$} & $31(3,359 / 10,887)$ & $49(5,308 / 10,887)$ & $20(2,220 / 10,887)$ \\
\hline & $(19-37)$ & $(45-53)$ & $(15-28)$ \\
\hline & $(518 / 2,828-1,227 / 3,320)$ & $(1,432 / 3,135-1,538 / 2,828)$ & $(509 / 3,320-772 / 2,828)$ \\
\hline \multirow[t]{3}{*}{ USA } & $37(10,224 / 27,466)$ & $42(11,615 / 27,466)$ & $20(5,627 / 27,466)$ \\
\hline & $(33-43)$ & $(39-44)$ & $(15-23)$ \\
\hline & $(1,359 / 4,145-1,704 / 3,969)$ & $(1,180 / 3,066-1,832 / 4,145)$ & $(590 / 3,969-717 / 3,074)$ \\
\hline
\end{tabular}

${ }^{\text {a }}$ Age standardized to the GLOW population; range of regional site rates in brackets

${ }^{\mathrm{b}}$ Belgium, Germany, The Netherlands, United Kingdom

${ }^{\mathrm{c}}$ France, Italy, Spain 
Table 2 Frequency of FRAX ${ }^{\mathrm{a}}$ risk factors and perceived fracture risk $(n=60,393)$

\begin{tabular}{lllll}
\hline Risk factor & Population (\%) & \multicolumn{2}{l}{ Perception of risk compared with women of same age (\%) } \\
\cline { 3 - 5 } & & Much or a little lower & About the same & Much or a little higher \\
\hline No FRAX risk factors & $39(23,772 / 60,392)$ & $42(9,639 / 22,953)$ & $48(10,982 / 22,953)$ & $10(2,332 / 22,953)$ \\
Single FRAX risk factor & & & & \\
Weight $<125$ lb $(57 \mathrm{~kg})$ & $16(9,436 / 57,900)$ & $32(2,928 / 9,142)$ & $42(3,814 / 9,142)$ & $26(2,400 / 9,142)$ \\
Previous fracture after age 45 years & $24(14,183 / 58,935)$ & $21(2,903 / 13,760)$ & $43(5,972 / 13,760)$ & $36(4,885 / 13,760)$ \\
Parental hip fracture & $17(9,189 / 53,663)$ & $28(2,537 / 8,941)$ & $46(4,155 / 8,941)$ & $25(2,249 / 8,941)$ \\
Current smoker & $9.2(5,484 / 59,816)$ & $31(1,647 / 5,299)$ & $50(2,627 / 5,299)$ & $19(1,025 / 5,299)$ \\
Current cortisone/prednisone use & $3.1(1,835 / 59,191)$ & $22(400 / 1,797)$ & $39(696 / 1,797)$ & $39(701 / 1,797)$ \\
Secondary osteoporosis & $21(12,403 / 57,974)$ & $31(3,750 / 12,003)$ & $45(5,415 / 12,003)$ & $24(2,838 / 12,003)$ \\
Aromatase inhibitor & $1.5(863 / 58,975)$ & $27(224 / 834)$ & $44(369 / 834)$ & $29(241 / 834)$ \\
Celiac disease/colitis & $2.6(1,540 / 58,921)$ & $26(396 / 1,495)$ & $42(627 / 1,495)$ & $32(472 / 1,495)$ \\
Diabetes type 1 & $3.9(2,341 / 59,434)$ & $29(646 / 2,235)$ & $47(1,040 / 2,235)$ & $25(549 / 2,235)$ \\
Menopause before age 45 & $15(8,632 / 59,399)$ & $33(2,730 / 8,372)$ & $45(3,787 / 8,372)$ & $22(1,855 / 8,372)$ \\
Alcohol $>20$ drinks/week & $0.5(290 / 59,813)$ & $34(97 / 287)$ & $46(133 / 287)$ & $20(57 / 287)$ \\
Two or more FRAX risk factors & $22(12,998 / 60,392)$ & $24(2,994 / 12,612)$ & $43(5,433 / 12,612)$ & $33(4,185 / 12,612)$ \\
\hline
\end{tabular}

${ }^{a}$ FRAX risk factors are weight, history of fracture, parental hip fracture, cigarette smoking, current cortisone/prednisone use, secondary osteoporosis, and alcohol use; secondary osteoporosis counts as a single risk factor

Approximately $10 \%(2,332 / 22,953)$ of women who reported none of the risk factors believed they were at increased risk of fracture (Table 2). This number rose to $39 \%(701 / 1,797)$ among women who were current users of glucocorticoids and to $36 \%(4,885 / 10,715)$ for those with a history of previous fracture. However, even among the $22 \%$ $(12,998 / 60,392)$ of women who had two or more FRAX risk factors, higher risk was perceived by just $33 \%(4,185 /$ $12,612)$ of women.

Among the $25 \%(14,477 / 56,906)$ of women who were without risk factors and without a diagnosis of osteoporosis or use of a prescription osteoporosis treatment, presumably conferring low risk for fracture, only $4.5 \%(633 / 14,066)$ believed themselves to be at increased fracture risk (Table 3). However, among women who reported having been given a diagnosis of osteoporosis, perception of increased risk for fracture was present in only $43 \%$ $(5,400 / 12,429)$. Similarly, only $41 \%(4,574 / 11,094)$ of women who were on treatment with antiosteoporosis medications believed that they were at heightened fracture risk. Among women with more than one risk factor, a reported diagnosis of osteoporosis, and who were currently using antiosteoporosis medications, 62\% (1,519/2,460) viewed themselves as having an increased fracture risk.

In the multivariable model, five of the seven risk factors showed statistically significant, independent associations with subjects' increased perception of risk (Table 4). The strongest of these was previous fracture, with an odds ratio of 3.3 (95\% confidence interval [CI] 3.2-3.5), followed by current use of cortisone or prednisone, and weight under $125 \mathrm{lb}$. Having been told by her doctor that she had osteoporosis or osteopenia also increased the likelihood that

Table 3 Perceived fracture risk by medical diagnosis or treatment status $(n=60,393)$

\begin{tabular}{|c|c|c|c|c|}
\hline \multirow[t]{2}{*}{ Medical diagnosis or treatment } & \multirow[t]{2}{*}{ Population (\%) } & \multicolumn{3}{|c|}{ Perception of risk compared with women of same age (\%) } \\
\hline & & $\begin{array}{l}\text { As much as or } \\
\text { a little lower }\end{array}$ & About the same as & $\begin{array}{l}\text { As much as or } \\
\text { a little higher }\end{array}$ \\
\hline $\begin{array}{l}\text { No osteoporosis diagnosis, FRAX risk factors, } \\
\text { or osteoporosis prescription medications }\end{array}$ & $25(14,477 / 56,906)$ & $48(6,749 / 14,066)$ & $48(6,684 / 14,066)$ & $4.5(633 / 14,066)$ \\
\hline On osteoporosis prescription medication & $20(11,365 / 58,107)$ & $20(2,207 / 11,094)$ & $39(4,313 / 11,094)$ & $41(4,574 / 11,094)$ \\
\hline Diagnosed with osteoporosis & $22(12,753 / 56,994)$ & $18(2,247 / 12,429)$ & $38(4,782 / 12,429)$ & $43(5,400 / 12,429)$ \\
\hline Diagnosed with osteopenia & $16(9,376 / 56,994)$ & $28(2,548 / 9,240)$ & $48(4,395 / 9,240)$ & $25(2,297 / 9,240)$ \\
\hline Neither osteoporosis nor osteopenia diagnosis & $61(34,865 / 56,994)$ & $43(14,624 / 33,799)$ & $49(16,556 / 33,799)$ & $7.8(2,619 / 33,799)$ \\
\hline $\begin{array}{l}\text { Osteoporosis diagnosis, }>1 \text { FRAX risk factor } \\
\text { and osteoporosis medication }\end{array}$ & $4.5(2,506 / 55,258)$ & $12(286 / 2,460)$ & $27(655 / 2,460)$ & $62(1,519 / 2,460)$ \\
\hline
\end{tabular}


Table 4 Associations of baseline risk factors for fractures with perceived higher-than-average fracture risk (compared with women of the same age; $n=45,125$ women with complete information on risk factors)

\begin{tabular}{lcc}
\hline Risk factor & Odds ratio & 95\% Confidence interval \\
\hline Weight $^{\mathrm{a}}<125 \mathrm{lb}(57 \mathrm{~kg})$ & 1.8 & 1.7 to 1.9 \\
Previous fracture & 3.3 & 3.2 to 3.5 \\
Parental hip fracture & 1.6 & 1.5 to 1.7 \\
Current smoker & 1.0 & 0.9 to 1.1 \\
Current glucocorticoid use & 2.6 & 2.3 to 2.9 \\
Secondary osteoporosis & 1.5 & 1.4 to 1.6 \\
Alcohol $>20$ drinks/week & 1.1 & 0.8 to 1.6 \\
Number of FRAX risk factors $(v s$ none) & \\
1 & 2.1 & 1.9 to 2.2 \\
2 or more & 4.5 & 4.3 to 4.8 \\
Osteoporosis diagnosis (vs neither) & 4.1 to 4.7 \\
Osteopenia & 4.4 & 9.4 to 11 \\
Osteoporosis & 10 & \\
\hline
\end{tabular}

${ }^{a}$ Estimates for weight, previous fracture, parental hip fracture, current smoker, current glucocorticoid use, secondary osteoporosis, and alcohol use are from a multiple logistic model with these seven risk factors (cindex 0.68); other estimates are unadjusted

${ }^{\mathrm{b}}$ Aromatase inhibitor treatment, celiac disease/colitis, diabetes type 1, and menopause before age 45

a subject would see herself at increased risk for fracture. Women with the diagnosis of osteoporosis were ten times (95\% CI 9.4-11) as likely, and those with osteopenia were 4.4 times as likely $(95 \%$ CI $4.1-4.7)$, to perceive heightened fracture risk.

\section{Discussion}

In our large, international observational study, most women generally considered their risk of future fracture to be lower than or the same as that of other women their own age. Findings across age groups and five geographic regions consistently showed that about $20 \%$ of women rated themselves at increased risk of fracture compared with about $35 \%$ who indicated they considered themselves at lower risk than their peers. However, among women who reported individual or multiple characteristics that actually put them at higher fracture risk than their peers, fewer than $50 \%$ recognized the increased risk. For example, only about one third $(4,885 / 13,760)$ of women with a previous fracture after age 45-fracture being the most potent risk factor for future fractures - viewed themselves to be at higher risk for subsequent fractures than their peers, while $21 \%(2,903 /$ 13,760 ) who had a prior fracture saw themselves as having lower risk. History of parental hip fracture, another strong predictor of future fractures, was also under-appreciated as an important risk predictor: only $25 \%(2,249 / 8,941)$ of women whose mother or father had broken a hip considered themselves to be at higher risk of fracture. The highest proportion of women who believed themselves to be at increased risk based on individual FRAX risk factors $(39 \%$, 701/1,797) were those who reported currently taking cortisone or prednisone.

Our data indicate that being given a diagnosis of either osteoporosis or osteopenia is most likely to raise a woman's perception of risk (odds ratios of 10 and 4.4, respectively), but even among women who had multiple FRAX risk factors, a diagnosis of osteoporosis, and current use of an osteoporosis prescription medication, only $62 \%(1,519 /$ 2,460 ) believe themselves to be at increased risk.

Previous research on the topic of self-perceived risk of osteoporosis and fracture is limited. Phillipov et al. [6] reported on a community-based sample from the South Australian Health Omnibus survey conducted in 1995. They found that twice as many women considered themselves to be at low as compared with high risk for developing osteoporosis. Perceived risk was not increased among women who actually had risk factors such as low body mass index, family history of fracture, or current smoking and was actually lower among older women. When Gerend et al. [7] asked over 400 women from 63 community organizations in Phoenix, Arizona to rate their chances of developing osteoporosis compared with other women of their own age, almost four times as many thought they were at lower risk than their peers. Giangregorio et al. [8] interviewed 127 patients $(82 \%$ women) who had experienced a fragility fracture in the preceding 2 years. Among this clearly highrisk group, only $43 \%$ thought that they were at increased risk of a future fracture.

Risk perception in GLOW for those taking medication for osteoporosis might be interpreted in two ways. Women could respond to the question using their assessment of premedication risk or considering on-treatment risk. When we examined patterns of risk perception for the subset of women on antiosteoporosis treatment, $41 \%(4,574 / 11,094)$ responded that their risk of fracture was greater than that of their peers, suggesting that premedication risk was being considered.

The reason why some women with risk factors fail to see themselves at heightened likelihood of fracture may be because they are unaware that characteristics such as prior fracture, parental history of hip fracture, low weight, smoking, early menopause, and high intake of alcohol contribute to risk. Support for such lack of recognition of well-established risk factors comes from Satterfield et al., who surveyed 400 US women aged 60 to 80 years in a random-digit dial telephone survey [14]. They found that women correctly identified risk related to smoking, exercise, calcium intake, and family history of fracture more 
than $60 \%$ of the time, but identified risks associated with early menopause, long-term steroid use, being thin, and use of alcohol less than $50 \%$ of the time. In the multivariable model reported here, neither smoking nor heavy alcohol use appeared significantly related to a perception of higherthan-average fracture risk. Furthermore, although significant odds ratios in our models indicate that some women appreciated the added risk conferred by five of the seven FRAX risk factors, the magnitude of these ratios (in the range of 1.5-3.4) suggest that the association is not large. Even having been given the "diagnosis of osteoporosis" or "currently taking antiosteoporosis medication" only raised risk awareness to levels of $43 \%(5,400 / 12,429)$ and $41 \%$ $(4,574 / 11,094)$, respectively.

The lack of accurate perception of fracture risk has adverse implications for successful fracture-prevention activities. Motivation for patients to seek and follow treatment is related to perceived susceptibility to a disease [15]. Cline et al. [16] reported that, among almost 1,000 women aged 45 and older residing in a Minnesota community, higher perception of susceptibility to osteoporosis was significantly associated with use of osteoporosis medications. Responsibility for accurately conveying risk for fracture to patients at increased risk will require careful explanation by the woman's physician, and this may be enhanced by the availability of risk assessment tools such as FRAX, which allows patients and physicians to work together to understand which patients have a high enough risk to require medication to lower that risk and which patients do not. It is also clear from the US Surgeon General's Report on Bone Health and Osteoporosis [17] that public health efforts to educate patients about risk factors as well as patients taking personal responsibility for their own health issues will be needed to help those at risk recognize their susceptibility to problems such as future fractures.

Strengths and limitations

Our intention in GLOW was to include subjects who were broadly representative of women aged 55 and older by attempting to enlist all women in this age group who were active patients in each physician's practice. As a nonrandomized, observational, practice-based study, however, GLOW is subject to biases in both the selection of physicians and the sampling and recruitment of patients. It is possible that participants would have greater interest in bone health issues and seek information, screening, and treatment more actively. Physicians who agreed to participate may not be representative of all physicians in a given area with respect to osteoporosis recognition and management. As increasing age is acknowledged to be the single most predictive risk of fracture, we attempted to mitigate its confounding influence by asking women to rate their personal risk in comparison to women of their own age. This strategy appeared to operate successfully, as the agestratified analyses shown in Table 1 indicated that distributions of perceived risk were similar among women across age groups.

Possible confusion among subjects between rheumatoid and other types of arthritis prompted us to drop the characteristic from our analysis. We also considered only current use of the glucocorticoids prednisone and cortisone as a risk factor where FRAX considers "ever use" a risk. Reports that have critically assessed increased susceptibility to fracture risk and the timing of glucocorticoid use suggest that current use is the most important predictor and that once use is discontinued, fracture susceptibility returns to baseline levels [18]. Aromatase inhibitors, while not specifically suggested as risk factors in the FRAX algorithm, were included because of their antiestrogenic properties and their association with bone loss and elevated risk of fractures in postmenopausal women [19].

\section{Conclusion}

Our data document, in a population of over 60,000 postmenopausal women from ten countries in North America and Europe, as well as Australia, that there is a consistent under-appreciation of personal risk factors for osteoporosis and fracture. Tools for diagnosis and risk assessment are widely available, as are safe and effective treatments when indicated, but if women fail to appreciate their own risks there will inevitably be a barrier to them receiving appropriate assessment and management. Improved education of both physicians and postmenopausal women about osteoporosis risk factors is needed.

Acknowledgments We thank the physicians and project coordinators participating in GLOW. Editorial support for the final version of this article, comprising of language editing, content checking, formatting, and referencing was provided by Sophie Rushton-Smith, Ph.D. Dr Boonen is senior clinical investigator of the Fund for Scientific Research, Flanders, Belgium (F.W.O.-Vlaanderen) and holder of the Leuven University Chair in Metabolic Bone Diseases.

Funding GLOW is sponsored by a grant from The Alliance for Better Bone Health (Procter \& Gamble Pharmaceuticals and sanofi-aventis).

Conflicts of interest Ethel S Siris - consulting fees: Amgen, Lilly, Merck, Procter \& Gamble, sanofi-aventis, Novartis.

Stephen Gehlbach - research and salary support: The Alliance for Better Bone Health (Procter \& Gamble Pharmaceuticals, sanofi-aventis).

Jonathan D Adachi-research and salary support: Amgen, Astra Zeneca, Eli Lilly, GlaxoSmithKline, Merck, Novartis, Nycomed, Pfizer, Procter \& Gamble, Roche, sanofi-aventis, Servier, Wyeth, 
Bristol-Myers Squibb; clinical trials: Amgen, Eli Lilly, GlaxoSmithKline, Merck, Novartis, Pfizer, Procter \& Gamble, Roche, sanofi-aventis, Wyeth, Bristol-Myers Squibb.

Steven Boonen - research grants: Amgen, Eli Lilly, Novartis, Pfizer, Procter \& Gamble, sanofi-aventis, Roche, GlaxoSmithKline; Speakers' bureau: Amgen, Eli Lilly, Merck, Novartis, Procter \& Gamble, sanofiaventis, Servier; honoraria: Amgen, Eli Lilly, Merck, Novartis, Procter \& Gamble, sanofi-aventis, Servier; consultant/advisory board: Amgen, Eli Lilly, Merck, Novartis, Procter \& Gamble, sanofi-aventis, Servier. Roland Chapurlat - research grants: French Ministry of Health, Servier, Lilly, Procter \& Gamble; honoraria from Servier, Novartis, Lilly, Roche, sanofi-aventis, Maxence Pharma; consultant/advisory board: Servier, Nycomed, Novartis, Maxence Pharma.

Juliet Compston-consultancy: Servier, Shire, Nycomed, Novartis, Amgen, Procter \& Gamble, Wyeth, Pfizer, The Alliance for Better Bone Health, Roche, GlaxoSmithKline; speaking engagements (with reimbursement, travel and accommodation): Servier, Procter \& Gamble, Eli Lilly; research grants: Servier R\&D, Procter \& Gamble.

Cyrus Cooper - consultancy and lecturing: Amgen, The Alliance for Better Bone Health, Eli Lily, Merck Sharp and Dohme, Servier, Novartis, Roche-GSK.

Pierre Delmas: None.

Adolfo Díez-Pérez - honoraria: Novartis, Eli Lilly, Amgen, Procter \& Gamble, Roche; Expert witness for Merck-consultant/advisory board: Novartis, Eli Lilly, Amgen, Procter \& Gamble; research and salary support: Novartis, Eli Lilly, Amgen, Procter \& Gamble, Roche. Frederick H Hooven - research and salary support: The Alliance for Better Bone Health (Procter \& Gamble Pharmaceuticals, sanofi-aventis). Andrea LaCroix - research and salary support: The Alliance for Better Bone Health (Procter \& Gamble Pharmaceuticals and sanofi-aventis). J Coen Netelenbos-research grants: sanofi-aventis, Procter \& Gamble; Speakers' bureau: Procter \& Gamble; honoraria: GP Laboratories; consultant/advisory board-Procter \& Gamble, Roche, GlaxoSmithKline, Nycomed.

Johannes Pfeilschifter - research grants: AMGEN, Kyphon, Novartis, Roche; equipment: GE LUNAR; Speakers' bureau: AMGEN, sanofiaventis, GlaxoSmithKline, Roche, Lilly Deutschland, Orion Pharma, Merck Sharp and Dohme, Merck, Nycomed, Procter \& Gamble; advisory board: Novartis, Roche, Procter \& Gamble, TEVA.

Maurizio Rossini: None.

Christian Roux - research and salary support: Alliance, Amgen, Lilly, Merck Sharp and Dohme, Novartis, Nycomed, Roche, GlaxoSmithKline, Servier, Wyeth; consultant/advisory board-Alliance, Amgen, Lilly, Merck Sharp and Dohme, Novartis, Nycomed, Roche, GlaxoSmithKline, Servier, Wyeth.

Kenneth G Saag-Speakers' bureau: Novartis; consulting fees/other remuneration: Lilly, Merck, Novartis, Amgen, Roche, Procter \& Gamble, sanofi-aventis; research support: Lilly, Merck, Novartis, Amgen, Procter \& Gamble, sanofi-aventis; advisory committee: Lilly. Philip Sambrook-honoraria: Merck, sanofi-aventis, Roche, Servier; consultant/advisory board: Merck, sanofi-aventis, Roche, Servier. Stuart Silverman — research grants: Wyeth, Lilly, Novartis, Alliance; Speakers' bureau: Lilly, Novartis, Pfizer, Procter \& Gamble; honoraria: Procter \& Gamble; consultant/advisory board: Lilly, Amgen, Wyeth, Merck, Roche, Novartis.

Nelson B Watts-speaking fees, consulting fees, and/or research support: Amgen, Novartis, Procter \& Gamble, Eli Lilly, Novo Nordisk, sanofi-aventis.

Ms Wyman: None.

Susan L Greenspan - research grant and support: Lilly, Procter \& Gamble, Novartis, Amgen, Wyeth, Zelos; honoraria for CME speaking: Procter \& Gamble; consultant/advisory board: Amgen, Procter \& Gamble, Merck.
Open Access This article is distributed under the terms of the Creative Commons Attribution Noncommercial License which permits any noncommercial use, distribution, and reproduction in any medium, provided the original author(s) and source are credited.

\section{References}

1. NIH Consensus Development Panel on Osteoporosis Prevention Diagnosis and Therapy (2001) Osteoporosis prevention, diagnosis, and therapy. JAMA 285:785-795

2. Cranney A, Guyatt G, Griffith L, Wells G, Tugwell P, Rosen C (2002) Meta-analyses of therapies for postmenopausal osteoporosis. IX: Summary of meta-analyses of therapies for postmenopausal osteoporosis. Endocr Rev 23:570-578

3. Sambrook P, Cooper C (2006) Osteoporosis. Lancet 367:2010 2018

4. Elliot-Gibson V, Bogoch ER, Jamal SA, Beaton DE (2004) Practice patterns in the diagnosis and treatment of osteoporosis after a fragility fracture: a systematic review. Osteoporos Int 15:767-778

5. Giangregorio L, Papaioannou A, Cranney A, Zytaruk N, Adachi JD (2006) Fragility fractures and the osteoporosis care gap: an international phenomenon. Semin Arthritis Rheum 35:293-305

6. Phillipov G, Phillips PJ, Leach G, Taylor AW (1998) Public perceptions and self-reported prevalence of osteoporosis in South Australia. Osteoporos Int 8:552-556

7. Gerend MA, Erchull MJ, Aiken LS, Maner JK (2006) Reasons and risk: factors underlying women's perceptions of susceptibility to osteoporosis. Maturitas 55:227-237

8. Giangregorio L, Papaioannou A, Thabane L, DeBeer J, Cranney A, Dolovich L, Adili A, Adachi JD (2008) Do patients perceive a link between a fragility fracture and osteoporosis? BMC Musculoskeletal Disorders 9:38

9. Kanis JA, on behalf of the World Health Organisation Scientific Group (2008) Assessment of osteoporosis at the primary health care level. WHO Scientific Group Technical Report, Who Collaborating Centre for Metabolic Bone Diseases, University of Sheffield, UK (available on request from the WHO Collaborating Centre or the IOF)

10. Hooven FH, Adachi JD, Adami S, Boonen S, Compston J, Cooper C, Delmas P, Diez-Perez A, Gehlbach S, Greenspan SL, LaCroix A, Lindsay R, Netelenbos JC, Pfeilschifter J, Roux C, Saag KG, Sambrook P, Silverman S, Siris E, Watts NB, Anderson FA Jr (2009) The Global Longitudinal Study of Osteoporosis in Women (GLOW): rationale and study design. Osteoporos Int 20:11071116

11. Haentjens P, Johnell O, Kanis JA, Bouillon R, Cooper C, Lamraski G, Vanderschueren D, Kaufman JM, Boonen S (2004) Evidence from data searches and life-table analyses for gender-related differences in absolute risk of hip fracture after Colles' or spine fracture: Colles' fracture as an early and sensitive marker of skeletal fragility in white men. J Bone Miner Res 19:1933-1944

12. EuroQol Group (1990) EuroQol-a new facility for the measurement of health-related quality of life. The EuroQol Group. Health Policy (Amsterdam, Netherlands) 16:199-208

13. Ware JE, Kosinski M, Dewey JE (2000) How to score version 2 of the SF-36 Heath Survey. Quality Metric, Lincoln

14. Satterfield T, Johnson SM, Slovic P, Neil N, Schein JR (2000) Perceived risks and reported behaviors associated with osteoporosis and its treatment. Women Health 31:21-40 
15. Gerend MA, Aiken LS, West SG, Erchull MJ (2004) Beyond medical risk: investigating the psychological factors underlying women's perceptions of susceptibility to breast cancer, heart disease, and osteoporosis. Health Psychol 23:247-258

16. Cline RR, Farley JF, Hansen RA, Schommer JC (2005) Osteoporosis beliefs and antiresorptive medication use. Maturitas 50:196-208

17. US Department of Health and Human Services (2004) Bone health and osteoporosis: a report of the Surgeon General. Office of the Surgeon General, Rockville, http://www.surgeongeneral.gov/ library/bonehealth/content.html

18. van Staa TP, Leufkens HG, Cooper C (2002) The epidemiology of corticosteroid-induced osteoporosis: a meta-analysis. Osteoporos Int 13:777-787

19. Dunn BK, Ryan A (2009) Phase 3 trials of aromatase inhibitors for breast cancer prevention: following in the path of the selective estrogen receptor modulators. Ann NY Acad Sci 1155:141-161 